\title{
Digital fabrication in the process of creation of the parametric concrete fencings
}

\author{
Marcin Giedrowicz \\ Institute of Architecture and Spatial Planning; Poznan University of Technology, \\ 2 Jacka Rychlewskiego Street, 61-131 Poznan, Poland; \\ marcin.giedrowicz@put.poznan.pl (D) 0000-0002-3055-9222
}

\begin{abstract}
This paper is a summary of the research on parametric design methods and digital fabrication in architecture and industrial design. Through the author's projects, he presents how effective parametric designing process can be in contemporary architecture. This publication is a testimony of a long and full production process of a set of concrete fencings - from design part, through prototyping, digital fabrication, post-production, concreate fabrication and selling process. The design part of this research pertains to algorithmic design methods in Grasshopper software as well as presents a broad range of various technological aspects involved in the fabrication process. In the conclusion part of this paper, the author discloses his expectations towards the future of concrete fencing in Poland and describes a set of appropriate rules that foster a further development of this technology.
\end{abstract}

Keywords: parametric design, digital fabrication, concrete fencing, prefabrication, Rhinoceros, Grasshopper, CNC, detail

\section{Introduction}

Nowadays, concrete is no longer a mix of volcanic dust and sand. Since the end of ancient times, concrete has undergone an extensive technological evolution and has reached an exceptional level of quality. Its mechanical characteristics allow a wide range of flexibility and versatility, while components mixed into concrete, such as glass fibre, aggregates and chemical admixtures, additionally enhance its aesthetic qualities which are increasingly appreciated by architects. The fourth industrial revolution, driven by the correlation between the Internet, CNC machines, NURBS software, 3D printers and a building site, puts concrete in a particularly strong position. In regard to the development of contemporary architecture, concrete [1] has an opportunity to become a bridge between the traditional, economic and durable building engineering and the progressive parametric architecture. Therefore, the use of concrete as an execution tool in the technological process has the potential to revolutionise the contemporary building engineering. This article is a summary of the study conducted on the use of digital 
methods of fabrication, intended for the construction of precast concrete elements of fences as well as for the professional use of this technology in the process of developing a unique style.

\section{Research}

\subsection{Current situation}

Concrete fencing in Poland is continuously very popular and attracts an ever-growing interest since the 90 s of the last century, providing a more affordable alternative to fences made of steel, timber and brickwork. Among many advantages of precast concrete fencing is their durability, easy and quick production, short time of the execution of a purchase order and its low price. Not without reason, concrete fences quickly became a budget substitute for the fencing commonly used in Poland which in general, directly refers in its form to its more noble archetypes. Consequently, the aesthetics of concrete fences is disputable, to say the least, and is often criticised among architects. Amidst many critical opinions aimed at them, the most important ones seem to concern the degradation of aesthetics in public areas as well as a gradual rejection of the use of traditional solutions in Polish villages. The authorities of towns and villages are also aware of these problems, which often leads to implementing the spatial regulations (Local development plan / Outline planning decision) which forbid the use of concrete fences and fence walls. Despite those regulations, concrete fences are still being built in the rural areas of Poland, revealing the ineffectiveness of the law enforcement and execution, but also the lack of proper aesthetic awareness and difficult financial situation of people living in rural areas.

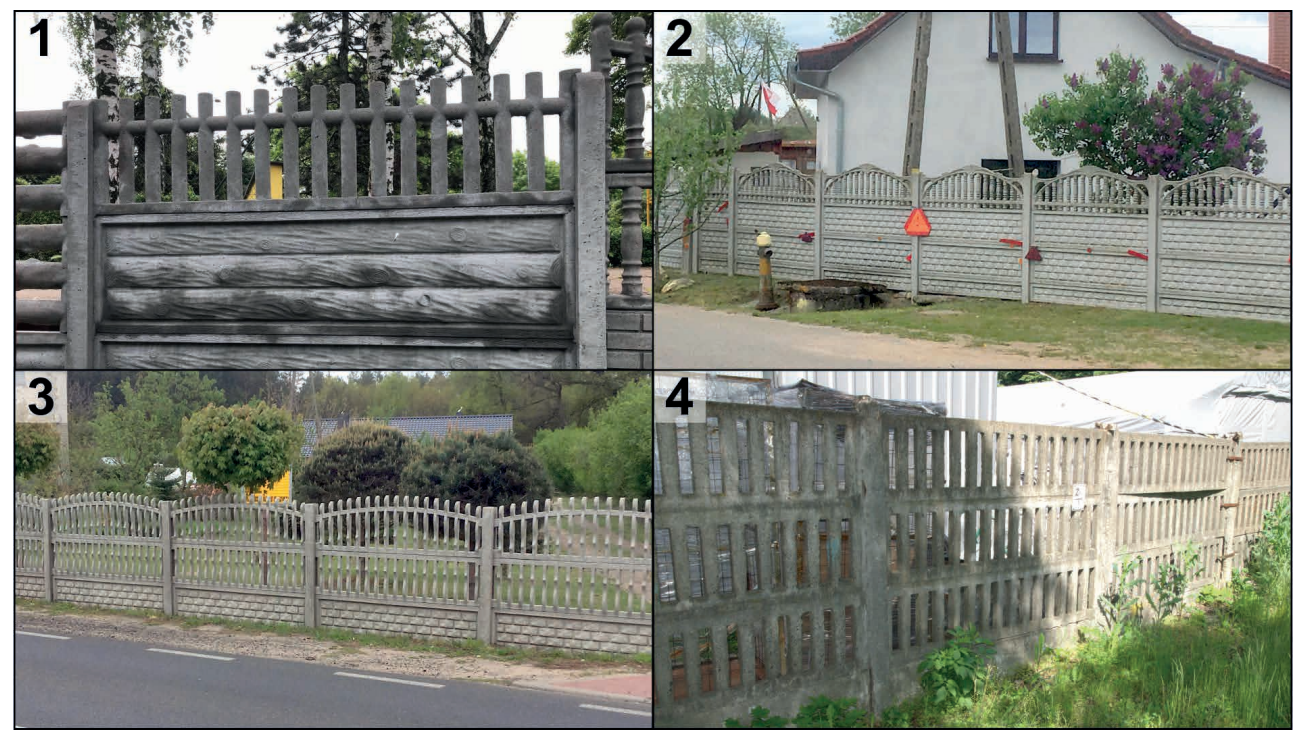

Fig. 1. Four groups of concrete fences in Poland - 1: timber imitation type in Chyby village, 2: brick imitation type in Karsko village, 3: steel imitation type in Łubianka village, 4: "socialist Poland" type in Przecław village. Source: [Marcin Giedrowicz]

Most of the concrete fences offered on the Polish market can be divided into four groups. The first one which is most frequently seen is the imitation of fences made from timber - full 
of details and quotes derived from woodworking technology and the decorative folk art. The second group of designs, encountered equally often as the first one, are copies of the solutions derived from masonry - those designs are drawing on different brickwork motifs, stone walls, traditional solutions characteristic of the rural and vernacular architecture. The third group of fencings includes imitation of the solutions typically used in the production of steel fencing - in the composition of which vertical and skew directions dominate, accented by slim elements that refer to steel bars. In this group of designs, we can equally often find framework compositions and openwork screens, falling into repeatable patterns. The fourth and the least developed group of designs are those that are deprived of direct aesthetic connections and references to traditional archetypes, constituting independent creation within the field of industrial design. These designs, having no complexes about the past, intentionally take advantage of such material as raw as concrete, creating design solutions that highlight the industrial nature of that building material. Few examples of that group of designs include the design of the railway fence developed at the times of the socialist Poland. A simple, orthogonal pattern with rhythmical, slim slots in the $\mathrm{ABAB}$ arrangement that had been used for many years for fencing of the railway areas, track superstructures, and farmsteads. That design has a very well-balanced proportions and ability to be connected into interesting arrangements when mixing it with a robust monolithic fencing design. However, due to its inferior quality of workmanship (use of very coarse aggregate fraction and concrete of poor quality), low durability and numerous associations with the communist period in Poland, this pattern has been perceived negatively [2].

\subsection{The task}

The primary research and design objective was to develop a catalogue of concrete fencing designs, which would be included in the commercial offer of the Poznan-based producer of precast concrete products.

The job entrusted was complex, which included [3]:

- expansion and development of the catalogue of concrete fencing patterns in the form of digital models,

- preparation of the fence mockups in scale 1:25 using 3D printing,

- making the fence prototypes in scale 1:1, with the assistance of CNC technology,

- making the casting moulds based on the wooden prototypes,

- implementation of concrete positives with the use of casting moulds.

The task aimed to create modern designs for concrete fences that break away from the current, negatively perceived market trends. The design of the developed collection, was supposed to be characterised by a fresh take on the material such as concrete and the most up-to-date design methods, assisted by $\mathrm{CNC}$ technology and parametric designing. The investor's concept was a new collection of fences to be supplied to more demanding customers, who will not only appreciate the design of the fence but will also place it in the appropriate area. This conceptual thinking that concerns new designs was based on the idea that the new product should find its place only in the urban or suburban areas, where it would complement the modern architecture.

\subsection{Methods}

The first stage of the design process consisted of creating an extensive collection of fence designs, according to the investor's guidelines, relating to technological limitations and costs of production. 


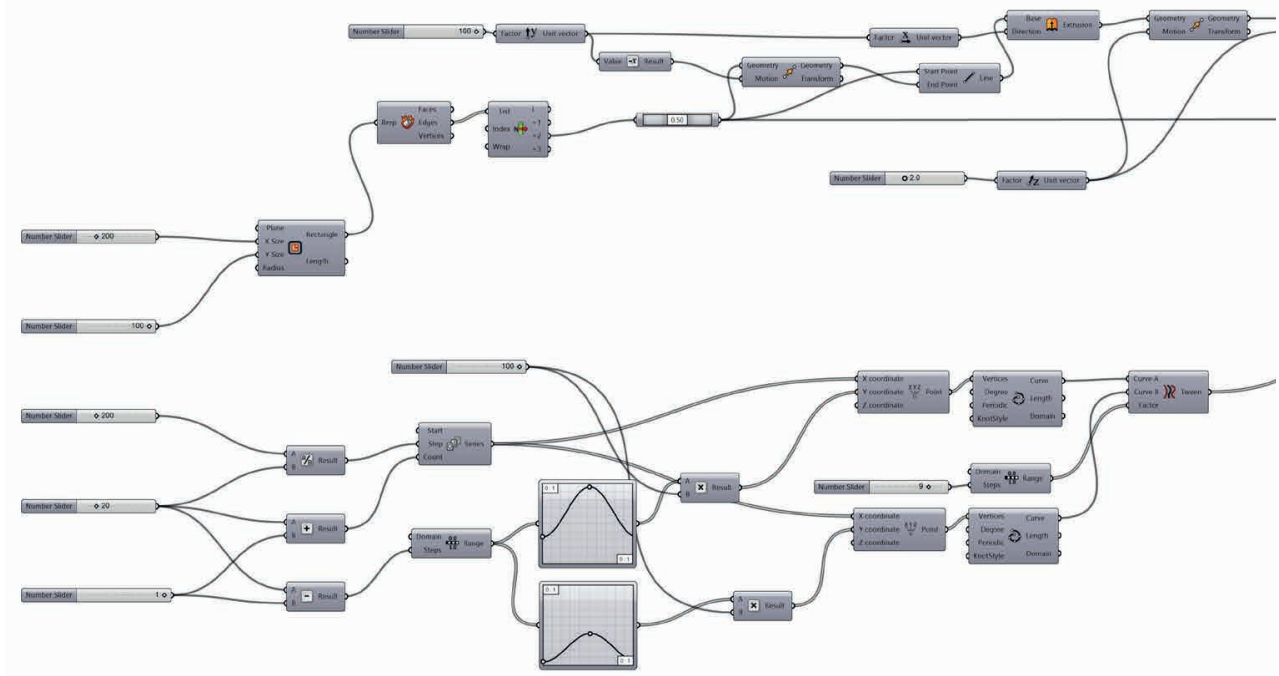

Fig. 2. "Wave" precast project - a crucial part of the algorithm created in a Rhinoceros / Grasshopper software. Source: [Marcin Giedrowicz]

The standard solution implemented in creating fencing is a use of panel with dimensions of 50x200x4.4 cm - most often 4 pieces of the panel are laid one upon each other, until repeatable surface area of 200x200x4.4 cm is obtained. A set of 4 panels that together make a pattern is placed in the concrete columns with the tee bar cross-section and then multiplied according to a plot perimeter. Consequently, the developed patterns were evaluated according to their commercial attractiveness and whether they could be produced using the casting method. This stage of the process was carried out in close cooperation with the investor who, on an ongoing basis, was excluding those patterns that did not have prospects for high sale and were generating too many production issues.

The underlying problems related to commercial attractiveness included:

- using too many openings (that resulted in the decrease of viewing insulation, and in consequence, lacking privacy on the fenced building plot),

- too expressive or complicated form (requiring 4 different casting moulds to be built, each with dimensions of $50 \times 200 \times 4.4 \mathrm{~cm}$ in order to obtain one repeatable pattern with dimensions of $200 \times 200 \times 4.4 \mathrm{~cm}$ ),

- using too large openings (lacking barrier against animals or possible burglars).

The most significant technological problems included:

- selection of appropriate material for fabrication of a prototype (that enable to mould using solvents and aggressive chemical substances),

- selection of appropriate technology to fabricate a prototype (additive, subtractive, and formative methods were considered),

- using the designs that are difficult to transport (susceptibility to breaking when stacking panels flat one upon the other),

- too thin side edges and corners (making reinforcement with steel bars impossible), 
- in the topology, using a pattern of right, obtuse and negative angles,

- using too small openings (not possible to be precisely cast from concrete).

In the result of the analysis carried out, five fencing designs were singled out with the following trade names:

NEO PRL - single-element design that is the modern interpretation of the railway fencing from the era of socialist Poland;

STRIPE - simple, minimalistic, single-element design with horizontal stripes, easily adaptable to the contemporary residential and service housing;

ATTRACTOR [4] - a complicated four-component design developed in the Grasshopper program, using the "Attractor" type algorithm;

WAVE - two-element design developed in the Grasshopper program, using the "Tween Curve" type algorithm;

LARSSEN - simple, minimalistic, single-element design with vertical stripes, inspired by Larssen steel profiles. These fences can create three different patterns by the use of just one single element.

The second stage of the work consisted of precise development of the geometry of individual fences, and then producing their trial mockups in scale 1:25 - for this purpose 3D printing technology was applied, in type FDM and the Zortrax M200 printer. The produced patterns did not prompt any fears or objections of the investor, who permitted to continue the work.

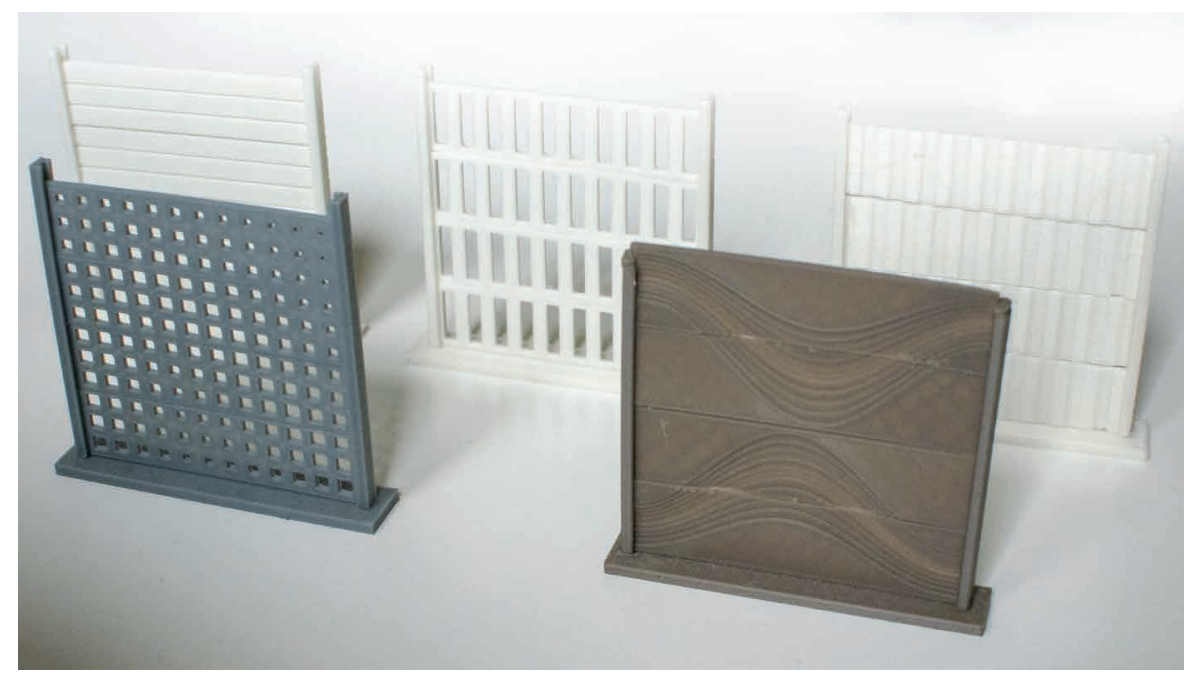

Fig. 3. Concrete fencing plastic models - effect of 3D printing process. First row from left: "ATTRACTOR" and "WAVE". Second row from left: "STRIPE", "NEO PRL” and "LARSSEN". Source: [Marcin Giedrowicz]

The third and the most complicated stage of the work was the production of fence prototypes - it was decided that a subtractive fabrication and wood-like material in the form of MDF boards would be used. The produced prototype fences were intended to serve at the later stage of the process as the positives to produce casting moulds from fibreglass and steel. The first two fence designs (NEO PRL and STRIPE) did not cause any significant technological problems - they were produced by means of the two and a half axis CNC mill planer. In both 
cases the double MDF board was used, with dimensions of $200 \times 50 \times 2.2$, placed one upon the other and integrated with wood screws. The entire working path of the mill was developed sequentially in Rhinoceros / Grasshopper, CorelDraw and ArtCAM programs. The ATTRACTOR [5] design of the fence, generated in the Grasshopper program consisted of as many as 4 individual elements with dimensions of $200 \times 50 \times 4.4$, which together contained in itself 124 unique openings [6]. The next significant technological limitation was a relatively small size of the openings - causing the wet concrete in the casting mould to turn into both, narrow and longitudinal shape. In consequence, a small mass of concrete placed in the narrow space could not be removed from the mould undamaged. This issue was solved by making holes; the angle of inclination of their internal wall was within the span of 80 to 85 degrees. Despite many attempts and many ideas of how to make cuts at such a small inclination angle and the 2,5-axis mill, it appeared to be impossible, or too time-consuming. In result, the decision was made to engage the 6-axis KUKA KR 60 HA robot arm, controlled by the library of Grasshopper - KUKA pre v2 program. The robot performed 124 openings in 4 subsequent stages of work - the MDF boards were mounted onto the provisional bench using clamps.

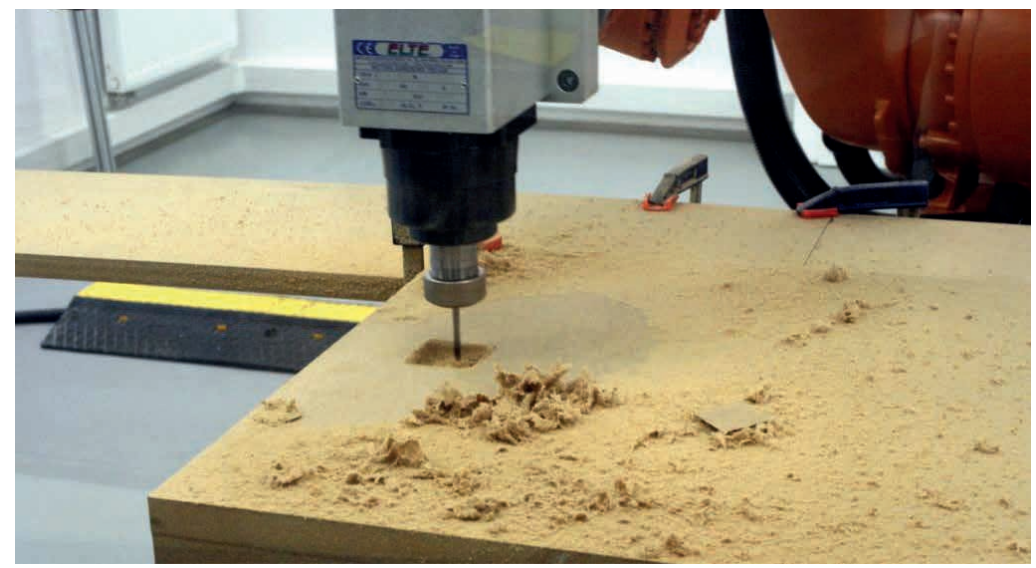

Fig. 4. 6-axis KUKA KR 60 HA robot arm during the milling process. Source: [Marcin Giedrowicz]

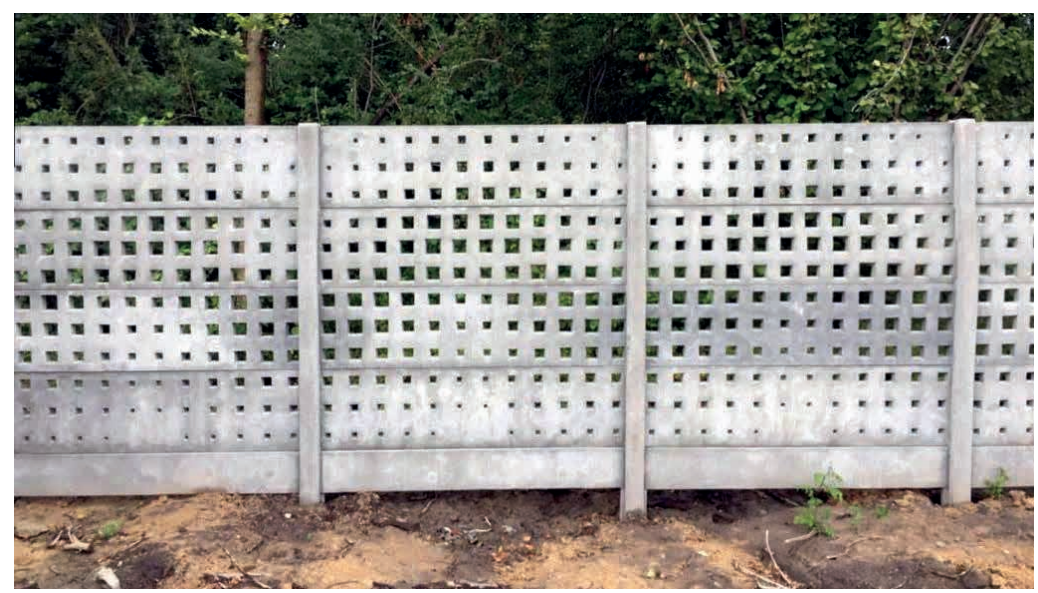

Fig. 5. The "Attractor" fencings realisation at the construction site. Source: [Marcin Giedrowicz] 
The fourth two-element "WAVE" [7] design was made using the 2.5 axis mill - even though the operation also required cutting out of internal walls with the inclination angle not smaller than 80 degrees. However, specific topology of that design enabled correct cutting to be made using two milling cutter types - the first cut using the flat mill and the second cut using the angular mill with the cutting plane equal to 45 degrees.

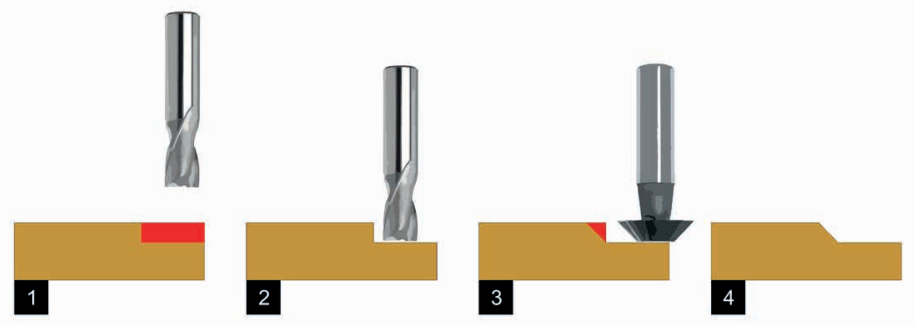

Fig. 6. The "Wave" subtractive digital fabrication process scheme. A standard flat drill conducted the first part of milling. Second part of milling required 45-degree drill. Source: [Marcin Giedrowicz]

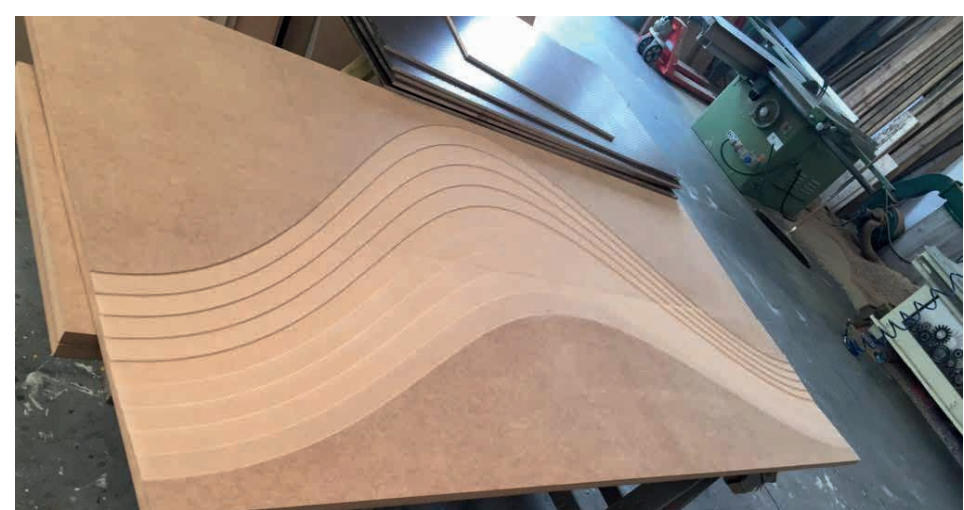

Fig. 7. The "WAVE" wooden positive just after the CNC milling process. Source: [Marcin Giedrowicz]

The same technology with drill changing was used to fabricate the last type of precast, which name is "LARSSEN".

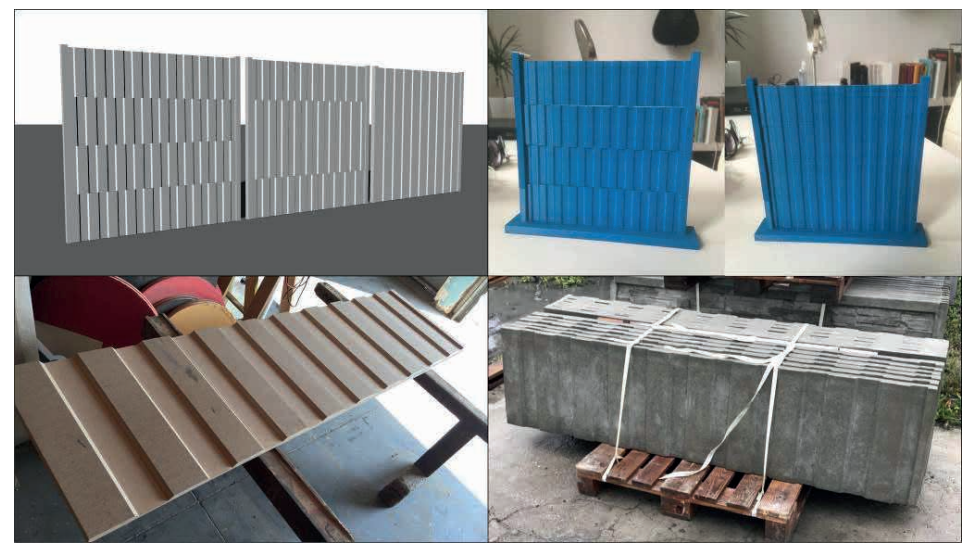

Fig. 8. The "Larssen" fencing development process - from the 3D model and plastic mockup, to positive wooden model and final product. Source: [Marcin Giedrowicz] 
The last stage of work was to create pouring moulds using the produced positives - the moulds were made from steel bearings equipped with four handles, filled with the impression made from fibreglass.

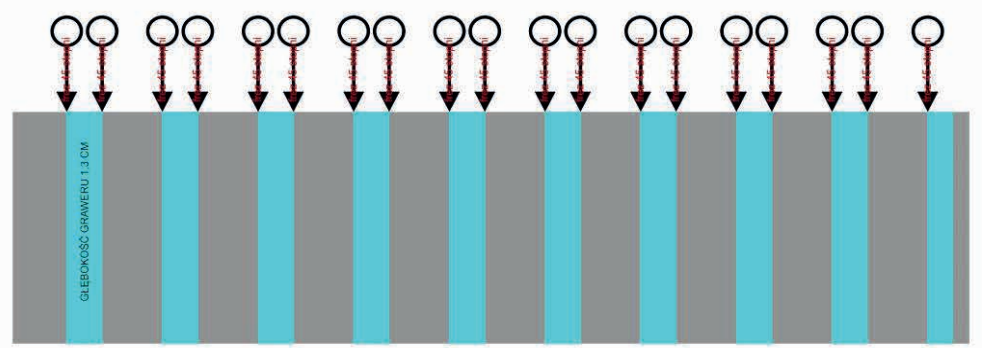

Fig. 9. 2D CorelDraw file with instructions to a CNC milling machine [8] how to create "Larssen" precast by a subtractive digital fabrication process. Source: [Marcin Giedrowicz]

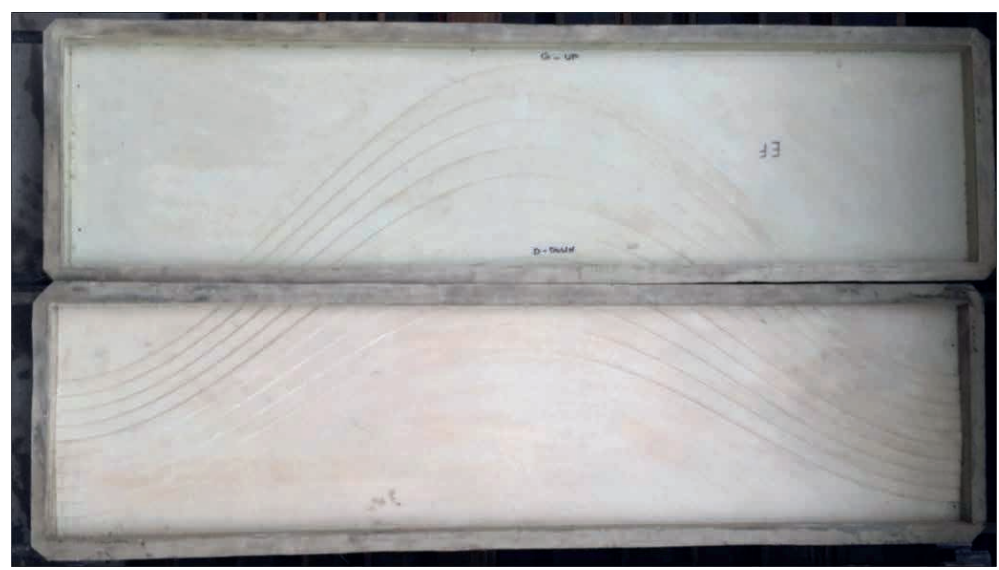

Fig. 10. Fibreglass mould [9] of "Wave" - a negative form before concrete filling process. Source: [Marcin Giedrowicz]

\subsection{Results}

The developed casting moulds were supplied to the investor who implemented them in the production line. In order to facilitate the separation of concrete from mould, the moulds were covered with an oily substance before filling them with $\mathrm{C} 30$. The process of mould filling and concrete surface levelling on the vibration table took about 60 seconds for a single element. After that time, the solidifying concrete element was separated from its mould and transferred to the drying area - the process of independent drying takes about 24 hours. In consequence, the trial castings of all the developed fence designs were produced to the satisfaction of the investor. The obtained moulds had no errors or geometric deformations. Shortly after that, mass production of the developed designs was started, where current statistics demonstrate very high sales of the "STRIPE" design, moderate sales of the "LARSSEN", "ATTRACTOR" and "WAVE" designs, and low sales of "NEO PRL" design. 


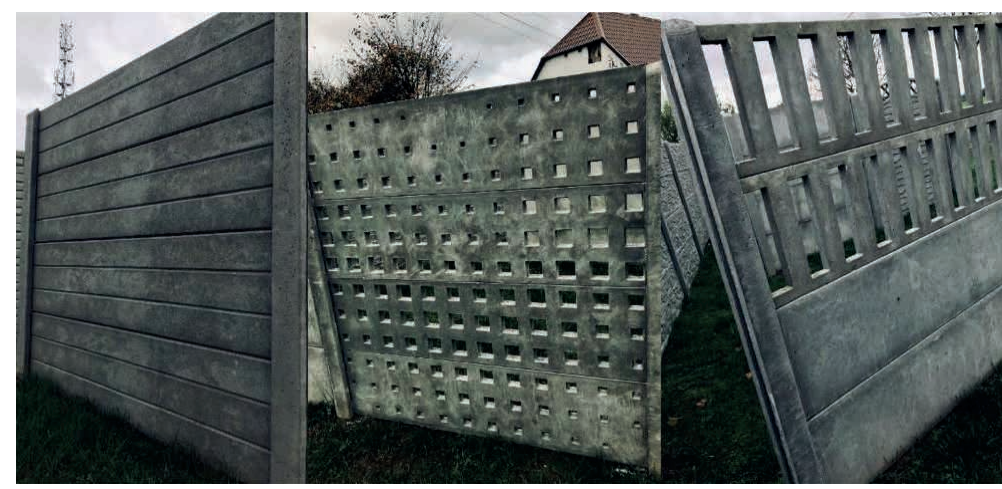

Fig. 11. Finished products - from left side: "Stripe", “Attractor", "Neo PRL”. Source: [Marcin Giedrowicz]

\section{Conclusions}

At present, the fencing market requires a revision of the current standards, adjusting the offer to the expectations of the more demanding customer and the higher aesthetic values. Concrete fencing can constitute an excellent addition to the contemporary urban and suburban architecture - however, under a few conditions, which include:

- use of concrete designs that do not imitate any other material or style,

- conscious application of CNC technology in order to develop precise and economical designs,

- treating concrete as an inspiring material, beautiful in itself,

- seeking for modern solutions, driven by technological progress [10].

Besides, the author represents the opinion that the ban on using concrete fencings in rural areas should be maintained, while demanding that traditional solutions are applied.

\section{References}

[1] Akos G., Parsons R., Foundations. The Grasshopper Primer Third Edition, digital publication, 2014, https://modelab.gitbooks.io/grasshopper-primer/appendix/A-3/0_about-this-primer.html.

[2] Asanowicz A., "Parametric Design - Tool, Medium or New Paradigm?”, eCAADe 2017 SHoCK!, Volume 2, Edited by Antonio Fioravanti, Stefano Cursi, Salma Elahmar, Silvia Gargaro Gianluigi Loffreda, Gabriele Novembri and Armando Trento, 2019 Roma, pp. 379-386.

[3] Bonenberg W., Giedrowicz M., Radziszewski K., Wspótczesne projektowanie parametryczne $w$ architekturze. Wydawnictwo Politechniki Poznańskiej, Poznań 2019.

[4] Cichocka J., Globa A., Attractors in architecture: attractor-based optimisation and design solutions for dynamical systems in architecture. Code of Space, 2016. http://hdl.handle.net/10536/DRO/ DU:30090743

[5] Helenowska-Peschke M., Parametryczno-algorytmiczne projektowanie architektury. Wydawnictwo Politechniki Gdańskiej, Gdańsk 2014.

[6] Januszkiewicz K., Giedrowicz M., "Concrete as component of the non-linear shaped structural "skin" in current architecture", in $8^{\text {th }}$ International Conference AMCM 2014 Analytical Models and New Concepts in Concrete and Masonry Structures, Wrocław 2014.

[7] Kozina I., Polski Design. Wydawnictwo SBM, Warszawa 2015. 
[8] Natividade V., "Digital Design and Fabrication of Freeform Concrete Blocks", in Computing for a better tomorrow. Łódź 2018, vol. 1, pp. 743-752.

[9] Paixao J., Fend F., "Break It Till You Make It", in Computing for a better tomorrow. Łódź 2018, vol. 1, pp. 753-762.

[10] Tedeschi A., AAD Algorithms-aided Design: Parametric Strategies Using Grasshopper. Le Penseur Publisher, Brienza 2014. 